Illinois State University

ISU ReD: Research and eData

Faculty and Staff Publications - Milner Library

Milner Library

$10-2018$

\title{
Document Delivery as a Supplement or Replacement for Serial Subscriptions
}

Julie A. Murphy

Illinois State University, jamurph@ilstu.edu

Chad E. Buckley

Illinois State University, cebuckle@ilstu.edu

Follow this and additional works at: https://ir.library.illinoisstate.edu/fpml

Part of the Library and Information Science Commons

\section{Recommended Citation}

Murphy, Julie A. and Buckley, Chad E., "Document Delivery as a Supplement or Replacement for Serial Subscriptions" (2018). Faculty and Staff Publications - Milner Library. 137.

https://ir.library.illinoisstate.edu/fpml/137

This Article is brought to you for free and open access by the Milner Library at ISU ReD: Research and eData. It has been accepted for inclusion in Faculty and Staff Publications - Milner Library by an authorized administrator of ISU ReD: Research and eData. For more information, please contact ISUReD@ilstu.edu. 
Problem Solved!

Document Delivery as a Supplement or Replacement for Serial Subscriptions

Julie A. Murphy, Column Editor

Collection Assessment Librarian, Milner Library, Illinois State University, Campus Box 8900, 201 North School Street, Normal, IL, 61790; USA; email: jamurph@ilstu.edu

Julie A. Murphy, Contributor

Collection Assessment Librarian, Milner Library, Illinois State University, Campus Box 8900, 201 North School Street, Normal, IL, 61790; USA; email: jamurph@ilstu.edu

Chad E. Buckley, Contributor

Head of Collection Development, Milner Library, Illinois State University, Campus Box 8900, 201 North School Street, Normal, IL, 61790; USA; email: cebuckle@ilstu.edu

\begin{abstract}
:
Increasing serials costs and shrinking budgets present challenges for academic libraries to continue providing sufficient access to scholarly articles. Rapid document delivery services can serve as an effective means to fill the gap caused by serials cancellations. This column examines several of the existing document delivery service providers and addresses issues involved in their implementation.
\end{abstract}

Keywords: 
document delivery; interlibrary loan; collection development; electronic journals; Get It Now; AZ Academic Article Collection; ReadCube Access

1. The problem

The issue of continually rising serials pricing is familiar to all academic libraries. For decades librarians have battled to maintain existing subscriptions in the face of inflationary costs and insufficient funds, with additional pressure to add new subscriptions to support new programs or emerging research areas. While many publishers have instituted alternative pricing models in an effort to increase library sales, the overall trend causes increasing difficulty each year as librarians prepare to allocate their inadequate materials budgets.

In 2017 the average price of a serial title was $\$ 1,385$, a 5\% increase from the 2016 average of $\$ 1,314$, and an overall $43 \%$ increase from the 2013 average of $\$ 970$. Over the last five years serials pricing has consistently increased by an average of $6 \%$ each year, far outpacing inflation in the U.S. economy. The sciences suffer the worst, with an average chemistry journal costing $\$ 4,759$ in 2017, and physics not far behind at \$4,447 (Bosch \& Henderson, 2013, 2014, 2015, 2016, 2017).

Academic library budgets, meanwhile, have not managed to keep pace. Over a five year period from 2009 to 2014 , the average library materials budget increased by only $15 \%$ (or $3 \%$ per year), and the average library total expenditures increased by $8 \%$ overall. Over that same period, the total academic library materials expenditures as a percentage of total library expenditures increased from 43.54\% to $46.43 \%$ (Kryillidou \& Morris, 2011; Kryillidou, Morris \& Roebuck, 
2015). While the average library's budget continues to slowly increase, many libraries have been facing static or decreasing budgets. Over the same 2009-2014 period, the average academic library's expenditures per full-time user fell from $\$ 1,236.12$ to $\$ 1,216.96$, a decrease of $1.6 \%$ (Kryillidou \& Morris, 2011; Kryillidou, Morris \& Roebuck, 2015). Academic libraries' share of total university budgets has been steadily shrinking as well, dropping from an average of $3.67 \%$ in 1982 to $1.95 \%$ in 2009 (Kolowich, 2012).

In the face of these rapidly rising prices and slowly increasing or stagnant budgets, libraries have been forced to seek creative solutions to maintain their serials access while reducing overall costs. Without an influx of funding, libraries must find a sustainable way to reduce the cost of access while still meeting faculty and students' need for a broad and diverse variety of journals. Since many libraries can no longer afford to maintain all their current subscriptions, librarians need a model that can provide fast, reliable, and affordable access to full-text articles without a subscription.

2. An alternative to subscriptions

While ownership of print serials was once the primary way libraries provided articles to users, the availability of electronic articles via the Internet enabled the rise of other models. In the 1990's and 2000's it became increasingly common for libraries to license electronic access to resources rather than purchase and store a print copy outright. While much concern was expressed in the literature at the time about the implications of relinquishing ownership of library resources, financial pressures and familiarity with this model by both librarians and others on 
campus have shifted attitudes. Most libraries now value the provision of access to their users more highly than the ownership of resources, especially for periodicals.

The traditional subscription model is simply no longer sustainable when inflationary costs are high and library budgets grow slowly or are even stagnant or decreasing. When faced with the need to cancel existing subscriptions to journal titles, libraries can follow a number of approaches. These range from allowing campus departments to identify titles they no longer consider critical, to targeting high cost titles regardless of use, to systematically assessing cost per use for all titles and canceling those above a certain cost per use threshold.

While many libraries have adopted patron driven acquisition models for ebooks, they are increasingly moving to hybrid models for serials which combine traditional subscriptions with pay-per-view access to content from selected high cost-per-use titles. Document delivery of individual articles is the typical pay-per-view model used by libraries for serials content. This can be totally unmediated, unmediated with some limits, or mediated by library staff. Corporate and other library types have been using commercial document delivery services to replace or supplement interlibrary loan (ILL) for quite some time, so pay-per-view for articles is nothing new. The newest development, however, is integrating document delivery with a library's OpenURL (Open Uniform Resource Locator) link resolver so that individual high-quality portable document file (PDF) versions of articles may be seamlessly requested and received by users with minimal intervention by library staff.

Cost per use analyses are often favored for identifying candidates for this type of access. Such analysis can quickly identify journal titles where it may be more cost effective to cancel a journal 
title subscription and rely on ILL or document delivery to supply the limited number of needed articles. To calculate cost per use figures, libraries must first have reliable usage statistics. Determining actual use is not without its issues. Many libraries do not collect any kind of usage statistics for their print journal collections, which makes this portion of the collection very difficult to evaluate. Even if they do, reshelving statistics may not accurately reflect total annual use since patrons might reshelve print issues on their own after browsing. For e-journals where publishers regularly make COUNTER-compliant usage statistics available, these may also not reflect total annual usage of a particular title for an institution. Patrons can retrieve open access versions of articles from off-campus without going through the library's proxy server, and that usage is never counted and credited to the institution. They may also acquire electronic copies from colleagues at other institutions without realizing there are legal ramifications to doing so. This questionable usage is also not included in library usage statistics.

For high cost-per-use journals, other options are available. Either standard ILL or document delivery can be used to legally supply articles from canceled titles depending on the acceptability of the delivery time. The turnaround time for accessing a subscribed title is, of course, instantaneous. ILL can often take several days for a requested article to arrive, with reported average times of less than 11 hours (Hendler and Gudenas, 2016) or 1.97 days (Jarvis and Gregory, 2016). Document delivery services fall somewhere in between with an average turnaround time of minutes for most requests, but it can still take hours or even days in extreme cases. Jaskowiak and Spires (2016) examined usage of ILLiad interlibrary loan service and Get It Now after the document delivery service was implemented at one university and found that as titles became available via Get It Now, ILLiad usage declined significantly. 
While costs for subscriptions are fixed (albeit subject to annual inflation), the total annual cost for ILL or document delivery of a specific title can fluctuate widely from year to year since it depends on usage. The cost per request for ILL is often around \$30. Jarvis and Gregory (2016) cited an average ILL cost of $\$ 35$, not including staff costs. Document delivery costs range from $\$ 0$ for open access title requests to $\$ 98$ for articles from more expensive publishers. The typical cost for a document delivery article averages \$24-51 based on experiences at Illinois State University. There are a range of payment options available, including automatic deduction from a deposit account, payment at the time of request, or invoices at regular intervals.

The cost per use threshold for canceling a subscription is typically close to the cost for an average ILL or document delivery transaction. If a subscription has a consistent cost per use greater than $\$ 30-50$, relying on ILL or document delivery should be considered. For example, a journal costing $\$ 5,000$ per year but receiving only 10 uses per year has a cost per use of $\$ 500$ per use. Those same 10 articles per year acquired via ILL or document delivery would cost about $\$ 300$ annually for a net savings of about $\$ 4,700$ per year. Multiplied across tens or hundreds of titles, the cost savings for switching from a subscription to a pay-per-view model can be significant. Because title usage can vary from year to year, it is a good idea to average uses over a 3 to 5 year period to account for such variability. Combining those usage figures with the subscription costs for the most recent invoicing period will yield current cost per use figures for existing subscriptions.

Because ILL and document delivery costs are less predictable and can vary widely from year to year for a particular title, libraries should regularly examine the cost effectiveness of titles selected for these access methods. Those titles where annual ILL or document delivery costs 
greatly exceed the annual subscription cost should be moved or returned to an annual subscription. Theoretically, because canceled titles had low usage, the annual number of requests from ILL or document delivery should not be high. However, usage could increase beyond initial counts due to changes in the curriculum or research interests at an institution. In this case the access model should be reevaluated.

\section{Specific options}

A number of options are available for document delivery/pay-per-view to provide articles from unsubscribed content directly to patrons. Some individual publishers allow libraries to set up deposit accounts or use tokens to provide individual journal articles via document delivery, although other alternatives have appeared in recent years. Commercial document delivery suppliers also offer services to libraries and can provide content from multiple publishers, some of which can be used directly by patrons. Get It Now from the Copyright Clearance Center and A-Z Academic Article Delivery Collection from Reprints Desk are two of the better known options. Other unmediated document delivery possibilities include ReadCube Access, DeepDyve, and Ingenta Connect.

\subsection{Get It Now}

Get It Now (http://www.copyright.com/academia/get-it-now/) from the Copyright Clearance Center was started in 2011 and offers articles from more than17,000 academic journals and 130 participating publishers. Patrons may request articles $24 / 7$ with a delivery time of typically less than 15 minutes. Full-color, high quality PDFs are delivered directly to requestors via email. Get 
It Now can be used with six different OpenURL link resolvers to provide seamless access to users (Copyright Clearance Center, n.d.). The service may be either mediated by librarians reviewing requests or unmediated with requests automatically being processed. Unmediated requests must adhere to specified limits, such as users making more than a specified number of requests in a given time period. They also offer a hybrid model where requests may be reviewed during business hours but are unmediated after hours. Payments may be made via a deposit account or invoiced monthly or semi-monthly. The cost per article ranges from $\$ 9-\$ 98$ per article depending on the publisher, with an actual average cost of about $\$ 26.64$ per article at Illinois State University (Copyright Clearance Center, n.d.).

\subsection{A-Z Academic Article Collection}

\section{A-Z Academic Article Collection (http://info.reprintsdesk.com/academic-articles) from Reprints}

Desk is another well known commercial service available to academic libraries. It began in 2008 and covers all academic disciplines. Over 40,000 journals plus chapters from more than a quarter million books are available from more than 100 publishers. Supplementary materials from journals are also included. High quality native PDFs are accessible 24/7. Both mediated and unmediated options are available. The service works with all major link resolvers, with the A-Z Academic Article Collection order form being available as a target. Delivery time for requested articles is typically a matter of minutes, and some articles can be instantly streamed to the user's browser. Cost per article ranges from $\$ 0$ for open access titles to over $\$ 60$ with an average cost of about $\$ 30$ (Reprints Desk, n.d.). 


\subsection{ReadCube Access}

ReadCube Access (https://www.readcube.com/libraries) initially began as a service aimed at individuals for the purpose of managing PDFs and citations. It offers the ability to link to a user's home library proxy and SFX servers to provide access to content available from the institution's library. For unowned content, users can browse the first page of an article free of charge and then rent an article for 48 hours to use only within the ReadCube platform (with some digital rights management restrictions on printing) or purchase a PDF for unrestricted use (ReadCube, n.d.). In 2015 only Nature Publishing Group content was available, but it has since expanded. Site-wide pricing is available upon request, and Parker (2014) noted that ReadCube "supports a demanddriven model based on single institution or consortia-based purchasing pools that are pre-set and metered." The University of Utah implemented a patron-driven acquisition service for journal articles via ReadCube Access (England and Anderson, 2013; England and Jones, 2014). England et al. (2015) also examined ReadCube Access' use at other libraries.

\subsection{DeepDyve}

DeepDyve (https://www.deepdyve.com) was initially released in 2008 as a rental model for individual researchers to gain access to individual articles (O’Leary, 2010). It offers free previews for five minutes and covers over 100 publishers (Brynko, 2013). DeepDyve offers group plans for more than ten researchers, but at this time does not sell group plans to academic institutions. 


\subsection{Ingenta Connect}

Ingenta Connect (http://www.ingentaconnect.com/about/librarianmenu) offers a document delivery service to both individuals and libraries in addition to regular open access and subscribed online journal content. It covers over 13,000 publications and allows libraries to set up a payment account for document delivery, as well as integrating with OpenURL link resolvers to make content seamlessly available to patrons (Ingenta Connect, n.d.).

4. Issues to consider in selecting a service

With any document delivery service, there are a number of general issues to consider before making the service available to patrons. The first is which journal titles to activate in the document delivery service. Will only canceled titles be made available? Or will selected unsubscribed titles also be included in order to make them accessible to patrons on a "trial" basis, with usage later assessed to determine whether an actual subscription would be cost effective? Another option is to make all titles from selected publishers available via document delivery.

Next, for titles which have been canceled locally, will document delivery be available only for post-cancellation content or for all issues covered by the service? It is certainly more cost effective to only activate post-cancellation content to avoid the possibility of paying for the same content twice. However, if print issues are located in remote storage areas, activating those older issues in a document delivery service can greatly increase timeliness of delivery to patrons. SFX can be used to prevent patrons from requesting document delivery of print material that is on-site 
by suppressing the document delivery option for such material, and other link resolvers have similar options. The decision to activate all years of a title via document delivery could also allow the possibility of withdrawing older, seldom used print volumes in order to save space. For titles not previously held by a library, this decision is similar. Is all available content activated or only volumes for recent years?

Another major consideration is whether to make document delivery mediated or unmediated. Mediated document delivery allows libraries to better control costs and ensure patrons are not using the service excessively. Library staff can screen requests to see if the item is already available locally, if the cost for an article is extreme, or if particular users are making large numbers of requests. Unmediated service makes the article request seamlessly available to patrons, although controls can still be established behind the scenes to prevent abuse. Limits on the article price or number of article requests per patron in a specified time period are standard options with many document delivery services.

Making document delivery discoverable by patrons is another very significant issue. Most services work with the various OpenURL link resolvers on the market. This makes specific articles readily discoverable within a library's databases. A user viewing an article of interest simply clicks on the link resolver icon, then sees an option for requesting that specific article from whatever document delivery service their library has activated. However, access to journals at the title level can be problematic. SFX, for example, cannot include document delivery journals in its A-Z list because they are not considered to be "owned" content. A local workaround solution implemented at Illinois State University was to purchase the BrowZine 
service from Third Iron. We then worked with Third Iron to get our document delivery titles from Get It Now added to BrowZine's title list alongside our regular SFX targets so that patrons can browse tables of contents at the title level from our Get It Now content and make seamless requests. Alma, however, can handle document delivery at the title level with no problem (Jarvis and Gregory, 2016). Adding document delivery titles to the library's online catalog and linking to the appropriate $\mathrm{A}-\mathrm{Z}$ service would also ensure that users searching there would not miss content that is available to them. The ideal manner for patrons to discover content available via document delivery would be at both the article and journal title level, and it is encouraging to see solutions to enable this access developing.

The method for submitting a document delivery request should ideally be as seamless to the patron as possible. A simple click through from a library's OpenURL link resolver followed by entering an email address is the best model. Requiring patrons to manually complete a form by entering article details is cumbersome, can lead to errors, and should be avoided. Most document delivery services integrate with link resolvers. Authentication to determine that a patron is eligible to place requests should take place early in the process when they first open a database or view a title in an $\mathrm{A}-\mathrm{Z}$ list.

Libraries providing document delivery services must also decide how to present the service to patrons. Because there is a fee for each article requested, patrons might balk at making requests if they knew the library would incur additional costs. The library must first ensure that patrons know they will not be charged personally and that the library is providing this service. The library must then decide whether to inform patrons in any way that the library is paying for each 
article requested. A best practice in this situation would be to make the costs hidden to patrons as much as possible. For example, at Illinois State University, the language displayed in SFX when a patron encounters an article available via Get It Now simply says "Request item via Get It Now (publisher name). Milner Library provides this service to you at no charge." That way, if patrons truly need a specific article which is available via document delivery, they will not hesitate to request it just as they would not hesitate to access a full-text article to which the library subscribes.

Promotion of the library's document delivery service must also be considered. A library can run the risk of making such a service too popular if it is publicized heavily. Users may quickly expend all of the funds a library has budgeted for document delivery if they discover their favorite titles are available. Reasonable promotion via instruction sessions, flyers, direct e-mail, newsletters, web pages, and social media can, however, be used to inform users that the service exists and how to access it. Libraries might consider phasing the service in using only a few initial titles in order to address problems and workflows before promotion efforts begin.

One benefit to using document delivery rather than relying solely on subscriptions is that it can create a very adaptable collection. Instead of having to allow time for initiating new subscriptions, activating a title via document delivery is essentially instantaneous. This is much faster than following the typical workflow for subscribing to a new journal title and waiting days to weeks for online access to be activated or even months for new print issues to begin arriving with the advent of a new calendar year. This can allow libraries to "adapt to constantly evolving patron information needs" (Jarvis and Gregory, 2016) and address the needs of new programs at 
academic institutions or even short-term research projects in a very timely manner. If a shortterm research project concludes, the associated document delivery title could simply be deactivated without any of the extra workflows associated with managing an actual subscription. A library might even "trial" new titles in document delivery to assess usage before considering a subscription. If a particular document delivery title is incurring excessive costs, it can be instantly deactivated in order to limit immediate budgetary expenditures. The journal title can then be moved to a subscription model if that would be more cost effective. When used in this manner, document delivery services could be an effective collection development tool, allowing libraries to expand access for a fraction of the cost of traditional subscriptions.

Regular review of document delivery titles is necessary to assess usage and costs for each title each year. If a particular title is being requested often, cumulative annual costs for articles may exceed the annual subscription cost, and the librarians might need to consider moving that title to a regular subscription. Of course, libraries would not want to cancel and re-subscribe to the same title repeatedly, so studying multi-year trends is ideal. The end goal is to be able to consistently examine each title in the "collection" in an evidence-based manner and provide access by the most cost effective means.

\section{Final thoughts}

Fast, reliable document delivery of individual articles directly to users with little to no mediation by library staff is now a feasible and sustainable alternative to expensive serial subscriptions. These services can be tailored to libraries' specific situations in order to provide access to 
content in a more cost effective manner. For high cost-per-use journals from major publishers, document delivery or even regular ILL can supply individual articles on demand, allowing libraries to provide access to content at a fraction of the original subscription cost. Unless library budgets increase significantly in years to come, librarians should continue to explore alternative models of access to serials content and integrate them into library workflows and budgets.

\section{References}

Bosch, S., \& Henderson, K. (2013, May 1). The winds of change. Library Journal, 138(8), 2833.

Bosch, S., \& Henderson, K. (2014, April 15). Steps down the evolutionary road. Library Journal, 139(7), 32-37.

Bosch, S., \& Henderson, K. (2015, April 15). Whole lotta shakin' goin' on. Library Journal, 140(7), 30-35.

Bosch, S., \& Henderson, K. (2016, April 15). Fracking the ecosystem. Library Journal, 141(7), 32-38.

Bosch, S., \& Henderson, K. (2017, April 15). New world, same model. Library Journal, 142(7), 40-45. 
Brynko, B. (2013, July/August). DeepDyve: Free preview of scholarly articles. Information Today 30:7, 30 .

Copyright Clearance Center. (n.d.). Get It Now. Retrieved from http://www.copyright.com/academia/get-it-now/

DeepDyve. (n.d.). DeepDyve. Retrieved from https://www.deepdyve.com/

England, M., \& Anderson, R. (2013, November). Patron-driven acquisition of journal articles using ReadCube at the University of Utah. Insights: the UKSG Journal 26(3), 267-71. doi: $10.1629 / 2048-7754.77$

England, M. \& Jones, P. (2014, January-June). Diversification of access pathways and the role of demand-driven acquisition: A case study at the University of Utah. Serials Librarian 66(14), 96-105.

England, M., Weisbrod, L., \& Jarvis, C. (2015). Article delivery using ReadCube Access: A report on use in five US libraries. Interlending \& Document Supply, 43(4), 189-98. doi: 10.1108/ILDS-07-2015-0023

Hendler, G.Y., \& Gudenas, J. (2016, October-December). Developing collections with Get It Now: A pilot project for a hybrid collection. Medical Reference Services Quarterly, 35(4), 363-371. doi: 10.1080/02763869.2016.1220751 
Ingenta Connect. (n.d.). For Librarians. Retrieved from

http://www.ingentaconnect.com/about/librarianmenu

Jarvis, C., \& Gregory, J. M. (2016, April-June). Get it? Got it. Good!: Utilizing Get It Now article delivery service at a health sciences library, Journal of Electronic Resources Librarianship, 28(2), 93-100. doi: 10.1080/1941126X.2016.1164556

Jaskowiak, M., \& Spires, T. (2016). The usage of ILLiad and Get It Now at a US medium-sized academic library over a three-year period, Interlending \& Document Supply, 44(2), 81-87.

Kolowich, S. (2012, Feburary 21). Smaller servings for libraries, Inside Higher Ed. Retrieved from http://www.insidehighered.com/news/2012/02/21/library-budgets-continue-shrinkrelative-university-spending\#ixzz2p4WQi552

Kryillidou, M., \& Morris, S. (2011). ARL statistics 2008-2009. Washington, DC: Association of Research Libraries.

Kyrillidou, M., Morris, S., \& Roebuck, G. (2015). ARL statistics 2013-2014. Washington, DC: Association of Research Libraries.

O'Leary, M. (2010, April). DeepDyve needs to come up for air. Information Today 27:4, 38-42. 
Parker, D. (2014, February). From publisher token systems to aggregation plays: eBook and journal article access is converging. Against the Grain, 26:1, 58-9.

ReadCube. (n.d.). Access for all: Flexible access options to fit every library budget. Retrieved from https://www.readcube.com/libraries.

Reprints Desk. (n.d.). The best ideas are borrowed: Academic docdel from reprints desk.

Retrieved from http://info.reprintsdesk.com/academic-articles 